Orbis Tertius, vol. XXIV, n 29, e107, mayo-octubre 2019. ISSN 1851-7811

Universidad Nacional de La Plata

Facultad de Humanidades y Ciencias de la Educación

Centro de Estudios de Teoría y Crítica Literaria

\title{
H. A. Murena, la recuperación de lo sagrado
}

\section{H. A. Murena: recovering the sacred}

Javier Mercado

Universidad Nacional de Córdoba, Argentina

parajaviermercado@gmail.com

\section{Resumen:}

Consideraremos aquí con los ensayos que Héctor Álvarez Murena redactó desde 1961 hasta su muerte. En particular, con La cárcel de la mente (1971), La metáfora y lo sagrado (1973), y El secreto claro (diálogos con D. J. Vogelmann, 1977). Nuestra hipótesis radica en que los textos de este periodo conforman una unidad y nos permiten valorar un Murena más interesado por la situación decadente de la cultura occidental. Su principal problema será la pérdida de lo sagrado en favor de un "pensar titánico" que acerca al hombre a la catástrofe. Al mismo tiempo, se evidencia un fuerte diálogo con representantes del "Pensamiento tradicional" de Occidente (Guénon y Burckhardt) y Oriente (Coomaraswamy, Lao Tse) que le permite complementar su pensamiento germánico de base (Heidegger y Benjamin) para dar posibles respuestas a la crisis moral, espiritual e intelectual del hombre moderno.

Palabras Clave: Profanación, Sacralidad, Arte, Religión, Modernidad.

\section{Abstract:}

We will work with the essays Hector Alvarez Murena wrote from 1961 until his death: particularly, La cárcel de la mente (1971), La metáfora y lo sagrado (1973) and El secreto claro (dialogues with D. J. Vogelmann, 1977). Our hypothesis posits that the texts of this period are a unit, which allows us to value Murena's greater interest in the decadence of Western civilization. His main problem is the loss of the sacred to a "titanic thought" that leads mankind to catastrophe. At the same time, there is a close dialogue with representatives of Western (Guenon and Burckhardt) and Eastern (Coomaraswamy and Lao Tze) "traditional thinking", which allows him to complement his German philosophical background (Heidegger and Benjamin) to offer possible answers to modern man's moral, spiritual and intellectual crisis.

KEYWORDs: Desecration, Sacredness, Art, Religion, Modernity.

\section{Murena, EL PENSADOR DE CAMINOS SOLITARIOS}

En el volumen 10 de la Historia crítica de la literatura argentina, Américo Cristófalo describe con justeza la trayectoria de H.A. Murena en el campo intelectual nacional desde principios de los 50 hasta los años posteriores a su muerte, acaecida en 1975. Según Cristófalo, existen ciertos términos que describen la posición de Murena; el principal, tal como reza el título de su artículo, podría ser "soledad”. Cabe destacar que la palabra no describe una condición absoluta, sino una progresiva transformación del escritor y ensayista que, desde un lugar periférico dentro de la revista Sur a principios de los 50, se irá reconcentrando en una soledad radical en los años siguientes hasta volverse "ilegible" en la década de los setenta (Cristófalo, 1999, p. 103). ${ }^{1}$

Esta reconstrucción es interesante porque repara en el progresivo ocultamiento $-\mathrm{o}$ retirada - del discípulo de Martínez Estrada del ensayo de interpretación nacional hacia una tipología textual diferente que, tal como describe Cristófalo, no encaja dentro de los esquemas de lectura de la generación de Contorno ni tampoco de los jóvenes críticos de los setenta. De hecho, desde las páginas de Contorno, "empezaba a construirse un juicio sobre Murena que llega hasta nosotros: espia sagrado, metafísico pesimista, esencialismo religioso, misticismo elitista (...). Años hegemónicamente sartreanos en la crítica y Murena al margen de toda rúbrica comprometida" (Cristófalo, 1999, p. 104).

Sería impreciso hablar de un corte drástico en la producción ensayística de Murena desde fines de los 50 hasta el 75; como se evidencia en el texto de Silvio Mattoni Las formas del ensayo en la Argentina de los años 50 (2003), existen ciertas preocupaciones y tradiciones filosóficas que ya están presentes en los textos anteriores a 
este período, sobre todo en Elpecado original de América. Pero estas continuidades no deben hacernos perder de vista que, a partir de los 60, la ilegibilidad de Murena para la crítica recrudece a partir de las formas y los temas de sus ensayos.

Pueden sindicarse las razones de esta progresiva retirada en el anacronismo que Murena comienza a profesar como forma de subversión en 1962 y que persistirá hasta el último de sus ensayos publicados en vida. La lucha contra el tiempo presente y, en particular, contra las dicotomías y filiaciones que imponen al individuo las formas del pensamiento moderno, harán que Murena reflexione cada vez con mayor detalle sobre lo religioso, lo sagrado y la metafísica. Por tanto, nos parece fundamental señalar esta diferencia que existe entre los ensayos finales del autor — La cárcel de la mente, que aparece en 1971; La metáfora y lo sagrado de 1973 y, finalmente, El secreto claro es editado de forma póstuma en 1977- y la producción anterior, que gravita sin dudas en torno a El pecado original de América.

Anclamos el adjetivo "finales" alrededor de 1961, ya que la mayoría de los trabajos de La cárcel de la mente son bastante anteriores a su publicación. Como informa la nota final de Visiones de Babel (Murena, 2002) "El ultranihilista" data de 1961, "El nombre secreto" aparece en 1969, y "El arte como mediador entre este mundo y el otro" data del mismo año. A su vez, El secreto claro se trata de un texto variable, con digresiones y sendas perdidas. Su estructura evidencia un texto que no estuvo pensado para ser leído, sino escuchado. Las conversaciones que H. A. Murena y D. J. Vogelmann mantuvieron durante los años 1971 y 1972 fueron trascriptas casi sin modificaciones en la versión final del texto y son un reflejo del pensamiento de ambos sin los filtros y pruritos de la escritura. Es inevitable señalar la coherencia y concordancia de estas charlas con La cárcel de la mente y La metáfora y lo sagrado. Fundamentalmente, porque en ellas se toma el pensamiento tradicional como llave para entender lo que le acontece al hombre actual y como brújula para dirimir hacia dónde se dirige el drama humano. El jasidismo, la cábala o el taoísmo son términos frecuentes del último Murena que también aparecen en los diálogos de Radio Municipal de Buenos Aires. ${ }^{2}$

Como señalamos, el tema predominante que nos permite sistematizar los últimos quince años de la producción de Murena se centra en la reflexión sobre la presencia o ausencia de lo sagrado en Occidente. Esto se vincula, por un lado, con la pregunta por la desorientación del hombre actual y su existencia en un mundo profano. Por otro, se asocia a las búsquedas religiosas de Murena, quien bucea en textos olvidados para hacer reverdecer el desierto espiritual moderno.

Como propone Guillermo Piro (2002), se puede entender la catena aurea que recorre los ensayos como "las notas sintomáticas de la lucha de una criatura por lo común desconcertada ante el caos especialmente perturbador de los tiempos y lugares que le fueron dados para vivir" (Murena, 2002, p. 13). En efecto, no es menor la presencia del desasosiego como eje que estructura la argumentación, la constante sensación de que al hombre del siglo XX le toca enfrentarse con un mundo en decadencia y ruinas. El hombre masa, masificado, desposeído de su propia individualidad es objeto de un análisis que no siempre se caracteriza por el optimismo en el futuro.

Los trabajos de Murena, en líneas generales, se proponen investigar el derrotero humano desde el Renacimiento en adelante para desentrañar en las razones ocultas del declive. Hay un afán constante de ir en busca de las causas profundas que subyacen a la presente decadencia. El interrogante por el fracaso del sujeto cartesiano occidental, podríamos decir, es el hilo que mantiene unido al texto.

En movimiento contrario, también busca el modo de sortear el abismo. Reacciona ante quienes proponen recetas que posibiliten una transformación. Pensar en una serie de pasos que puedan llevar a la redención es, en el fondo, un pensar tecnocrático. Murena huye del reino de la cantidad y señala hacia lo sagrado. El reencuentro con lo sagrado no es algo que se pueda enseñar mecánicamente, requiere una voluntad de introspección muy fuerte. Se entiende como un camino estrictamente individual, donde la idea de masa queda excluida totalmente. Una sociedad no es más que el conjunto de problemas o virtudes de cada uno de sus miembros y sería un error — desde su perspectiva — suponer que una sociedad puede ser más sana que sus 
integrantes. La transformación social no terminará por transformar a los individuos, sino al contrario. Es la transformación de los individuos la que posibilita la transmutación de una sociedad.

Nuestro recorrido por esta zona ilegible de la ensayística de Murena se propone, en principio, entablar un diálogo con las fuentes que explícitamente se señalan en los textos para poder, desde allí, organizar los ejes problemáticos más importantes que son retomados con insistencia por el autor durante los últimos quince años de su producción. No intentamos desarrollar una lectura puramente "esotérico-romántica" (Cristófalo, 1999, p. 105), como la realizada por Teresita Frugoni de Fritzsche (1985) —cuyo estudio, por otra parte, supera ampliamente al nuestro-, pero sí nos interesa poner en valor lecturas, autores y corrientes de pensamiento del siglo XX que se encuentran presentes en la obra de Murena. Particularmente, destacaremos el fuerte diálogo con la Escuela Tradicional de René Guénon y Titus Burckhardt. Profundizar en estas fuentes anacrónicas - si se nos permite el uso incorrecto del término- posibilitará resaltar con mayor claridad el cariz de las reflexiones de Murena durante este período, cuyo foco central ya no está puesto en la construcción de una ontología americana, sino en desentrañar las razones de la decadencia del occidente moderno.

\section{LAS FUENTES TRADICIONALES DE UN ANACRÓNICO POR ELECCIÓN}

En La cárcel de la mente se agolpan citas de René Guénon, Titus Burckhardt y Ananda Coomaraswamy. En función de estas referencias proponemos hablar de un viraje intelectual en los últimos quince años de la producción del autor. Nuestra primera tarea es reseñar algunas de las características de este viraje y las fuentes de las que se nutre. Para esto, los diálogos de El secreto claro son fundamentales, ya que bajo el tono cordial de la charla se abordan estos temas y autores.

Durante estas emisiones radiales se rescata con fuerza la figura de René Guénon. De hecho, en el diálogo titulado "La contrainiciación" (2005, p. 21-27) se trabaja con las ideas de iniciación y tradición en clave netamente guenoniana. A partir de esta referencia, Murena nos lleva al campo del "Esoterismo Cristiano" (Guénon, 2003). Con esta expresión hace referencia a una sabiduría tradicional que se encuentra más allá del cristianismo pero que se encarna materialmente en ella. Este saber esotérico es el núcleo central que comparten todas las religiones. La mostración que cada una de ellas hace del saber es diferente y particular. Así, existe siempre una faceta visible y abierta de toda religión, su cara exotérica. Ésta se complementa con una faceta invisible, interior y mistérica, su cara esotérica.

Mencionamos brevemente esta particularidad porque, durante todos los diálogos con Vogelmann, Murena demuestra un gran interés por la cara esotérica de las religiones. En el diálogo "El Tao, la técnica y el justo medio" (2005, p. 45-51) opta por el taoísmo y Lao Tsé frente al saber exotérico y social de Confucio. En "El deseo del mendigo" (2005, p. 53-58) vuelve con insistencia sobre el jasidismo, vertiente mística del judaísmo. Con "El agua del paraíso" (2005, p. 67-70) se interesa por el sufismo, es decir, el esoterismo islámico. Dentro de la tradición cristiana, trabaja sobre el Maestro Eckhart (2005, p. 76) y Angelus Silesius (2005, p. 115). Como queda claro en las charlas, Murena opta por el aspecto esotérico de las religiones. Y tal vez por esto pasa del judaísmo al islam o al cristianismo sin ningún tipo de problemas. No revisten gran importancia las diferentes formas externas.

A esto se debe sumar que, al hablar sobre arte en el texto "El arte como mediador entre este mundo y el otro" (2002, p. 400), no cita ninguna de las grandes referencias de su tiempo, sino que se apoya en el texto de Titus Burckhardt Principios y métodos del arte sagrado, en Simbolos fundamentales de las ciencias sagradas de Guénon, en textos sobre alquimia de Eugène Canseliet, y en La danza de Shiva de Ananda Coomaraswamy. Se trata en todos los casos de autores capitales de la corriente tradicionalista, cuyos estudios sobre religiones apuntan a los aspectos esotéricos.

En este recorrido por las referencias menos difundidas queremos agregar a Carl Gustav Jung. ${ }^{3} \mathrm{Si}$ bien el psiquiatra suizo no se dedica a la historia de las religiones comparadas, el peso de esta disciplina en su obra es fundamental, al tiempo que se erige como uno de los críticos centrales del "mundo sin dioses" forjado por la 
mentalidad racional europea. La importancia de lo inconsciente colectivo es remarcada en el apartado 15 de "El ultranihilista", donde afirma que "El arte de curar occidental había menospreciado — con total coherencia respecto a la $W$ eltanschauung de la que formaba parte - las fuerzas psíquicas irracionales que desempeñan en la dinámica de la salud un papel que aún no se sospecha siquiera” (2002, p. 301).

Siguiendo los argumentos del mencionado apartado 15 (y también en el 12), se advierte que Murena no piensa en sintonía con Freud, sino que opta por una definición de carácter junguiano. Como se aprecia en los ensayos de Civilización en transición (Jung, 2014) lo inconsciente es pensado por el autor suizo desde un punto de vista colectivo y social.

Como Jung, Murena también es reacio a pensar en términos de grupo, y mucho más si se considera al grupo como masa. La masa comporta la degradación del individuo humano, quien librado a las fuerzas de lo inconsciente ya que en el grupo prima lo que es común a todos. Por tratarse lo inconsciente colectivo de algo conformado biológicamente a lo largo de los milenios, un sujeto masificado está completamente desprotegido contra sus fuerzas inconsciente y puede ser manipulado a través de diferentes herramientas que el pensar titánico ha forjado para tales fines.

Cerramos aquí este recorrido por las fuentes de Murena. Lo fundamental aquí reside en comprender que, si bien el autor presenta una serie de continuidades en su obra, también existen nuevas sendas. En estos últimos ensayos permanecen latentes algunas preguntas iniciales, pero el énfasis radica en pensar la coyuntura de lo humano. El interrogante de ¿qué es ser un hombre en Latinoamérica? se ve desplazado por una nueva cuestión: ¿qué queda de humano en el hombre? ¿cómo gestionar los resabios de humanidad para reverdecer la civilización occidental?

\section{LA PROFANACIÓN DEL MUNDUS}

En la charla "La decadencia de nuestro tiempo", Murena y Vogelmann exponen la teoría de los ciclos cósmicos $(2005,33)$. Esta teoría observa que el universo no se desarrolla de acuerdo a un tiempo lineal e independiente de los eventos que sobre él se concitan, sino que tiene otra lógica de funcionamiento. Frente al tiempo cartesiano - plano y abstracto en todo sentido - la teoría de los ciclos apunta a una concepción diferenciada: el tiempo no es independiente de los sucesos que se dan en él; es más, tiempo y suceso están íntimamente relacionados, se rigen de acuerdo a lo que Guénon llama "signos de los tiempos" (1976). El tiempo marca cualitativamente los acontecimientos que sobre él se despliegan. En esta teoría, de claros ecos gnósticos e hindúes, se habla de un progresivo empobrecimiento del universo manifestado a partir del alejamiento del principio divino que la da origen.

La referencia primaria de este hecho es Los trabajos y los días de Hesíodo. La gradación de las edades Oro, Plata, Cobre e Hierro - responde al poeta helénico. Pero el origen de la teoría puede rastrearse hasta la India. De hecho, la teoría hindú de los ciclos cósmicos reza que todo el Manvatara (o "Día de Brahma") se divide en cuatro edades o Yugas (Guénon, 1966, p. 17-18).

La teoría de los ciclos descendentes es el marco imprescindible para comprender todas las afirmaciones de carácter político y sociológico que Murena realiza en La cárcel de la mente. De hecho, sin ella se vuelve oscura la desconfianza que siente por los sistemas de gobierno modernos, en todo conformes con un hombre de hierro que no aspira a una comprensión holística sino sólo material de su existencia. Encontrarnos en el Kali Yuga es el factor fundamental por el cual se ha perdido la clave simbólica de comprensión del devenir humano en la tierra. Murena afirma:

La historia es un criptograma que quizás tenga una sola interpretación definitivamente valedera, pero los hombres (...) nos servimos para descifrarlo de diversas claves, que varían con el lugar y el tiempo a que pertenecemos, y que nos lo aclaran según lo que más nos concierne. Con América se da el escandaloso caso de que (...) ha sido y es interpretada, inclusive por los americanos, según una clave puramente europea (2002, p. 224). 
No es posible ya una vera interpretatio porque se han perdido las claves, es decir, se desconoce la tradición espiritual. Este desconocimiento vuelve puro objeto material de estudio científico cualquier interrogante, que queda desprovisto de trascendencia y, esencialmente, de carácter simbólico. La historia, entonces, se vuelve materialismo histórico; el mundo, una cantera inagotable de recursos; el hombre, mano de obra para la producción. La existencia completa se desacraliza, el hombre está desvinculado del kósmos.

A raíz de la pérdida de la brújula simbólica, Murena considera que se extravía el sentido de lo sagrado no sólo en el tiempo, sino también en el espacio. El hombre moderno vive en una geografía completamente accidental - profana-; habita ciudades que se diseñan en función de las necesidades del comercio, pero no se piensan como catedrales para habitar. Retoma la noción de "geografía sagrada", presente ya en Mircea Eliade y René Guénon:

Existe sin duda una geografía mística — para darle un nombre que la distinga de la exclusivamente geográfica一, según la cual cada punto en la tierra posee una irradiación única, compleja y de algún modo fatídica. Esas radiaciones se hacen manifiestas - y a la vez se eclipsan - en la particular historia que se constela y estratifica en torno a cada punto terrestre (Murena 2002, p. 223).

La geografía sagrada es por completo ajena a cualquier habitante de la Europa moderna. Ese punto terrestre donde la historia se constela nos remite al ómphalos griego (Murena 2002, p. 276), el punto a partir del cual el caos se vuelve cosmos. Las culturas tradicionales manejaron esta noción y establecieron sus centros de peregrinación, santuarios, sitios sagrados y montañas mágicas. Tener un ómphalos es tener un centro que orienta filosófica, espiritual y socialmente.

Luego de Renacimiento el centro comienza a borrarse y se reemplaza por otro que nada comporta de sagrado. En estas condiciones, prima lo hostil en la vida:

el hombre es la bestia que ya no posee la ciega fuerza necesaria para errar por el caos de lo sin sentido y subsistir. En cambio, desde su cima de concentración psíquica sin precedentes y por cierto peligrosa (...), el hombre cuenta con el novedosísimo poder (...) de instaurar el orden, de fundamentar el sentido. Para erigir dicho orden, para "cosmizar" el caótico mundo en bruto, el hombre debe practicar la repetición ritual de los actos míticos con que los dioses crearon el cosmos en el principio. Y dado que los dioses impusieron su fiat creador mediante una irrupción de la sacralidad en el caos, la criatura humana, para hacerse de un mundo en el cual pueda morar, debe consagrar, sacralizar, ordenar el ámbito elegido (2002, p. 275).

Los dioses, los espíritus, los demonios desaparecen del "afuera", no son ya entidades autónomas que cohabitan el mundo de los humanos, ni es necesario conjurarlas. Todo conjuro, toda invocación a lo sagrado, toda sacralización del espacio, supone una fuerza contraria al caos que se desea conjurar. El hombre abandona la tierra sacra para ingresar a la racionalidad técnica. En el mundo sin misterio - del siglo XVIII en adelante - no son necesarias las protecciones de lo sagrado porque no hay nada de que protegerse. Dios abandona al hombre para retirarse a la morada de lo imposible.

En su soledad, el hombre descarta todos los ritos de cosmización —esos ritos ancestrales que Murena señala - e ingresa de lleno en lo profano. Mas, como advirtió Jung para la Alemania de entreguerras, esos dioses no se han retirado, simplemente se han ocultado. Ya no están en el afuera, pero se han vuelto enfermedades psíquicas que desatan verdaderas epidemias. Reintegrar el mundo de los dioses en el mundo de los hombres es necesario para que se vuelva a vivir en un kósmos.

La pérdida del espacio sagrado comporta también el caos en el diseño de las ciudades, pequeño mundo en que el hombre tradicional intentaba reflejar el orden cósmico. Por ello, las ciudades modernas - en especial las americanas - no tienen ritos de fundación ni una diagramación simbólica que las organice. Se trata sólo de asentamientos de gente, construidos sobre el ideal de la conquista, es decir, el saqueo de la guerra. Las ciudades post-renacentistas se convierten en un ejercicio de la precariedad y el desamparo de la mentalidad conquistadora, destructora. Son el mundo visto a través de los ojos del pensar titánico.

Murena recuerda que entre los ritos tradicionales de fundación se cavaba un pozo en el centro de la futura ciudad -ómphalos que también sería llamado mundus - y allí dentro se colocaba un puñado de tierra del 
lugar de origen del fundador con otras ofrendas, como frutos y miel (Murena, 2002, p. 393). El sentido del ritual aparece claro: propiciar la prosperidad y la abundancia en el nuevo lugar, al tiempo que remediar una afrenta: el abandono del lugar de origen. Viajar — como viaja hoy el turista o ayer el colono— no tiene sentido en las culturas tradicionales. El único viaje posible es el viaje de iniciación y se realiza con el objetivo de volver a la tierra de origen para cerrar el camino heroico. Porque la religación que prodigaba lo religioso era con los dioses, con los antepasados y con la tierra.

Finalmente, en una geografía profana y en un espacio profano, al hombre no le queda otra alternativa más que optar por un sistema de gobierno también profano. Aunque pueda soñar extemporáneo, Murena desconfía de las democracias modernas y se detiene en la noción de monarquía sagrada.

la democracia moderna que en 1789 inició una Blitzkreig ideológica y material que terminaría por derribar a los regímenes de los áristoi de todo Occidente para sustituirlos por los gobiernos de la bourgeoisie, tuvo que implantar (...) una égalité jurídico-económica que constituía el desmañado e ineficaz gesto con que la nación intentaba imitar y suplantar el amor de Dios hacia sus criaturas. (...) Pero a la larga la inicialmente benéfica égalité terminó por mostrar su verdadera esencia de inapropiado y por tanto nocivo Ersatz del amor de Dios (...) [La] sociedad de masas ha terminado por crear, mediante el mazo de la igualdad y los granos de las criaturas, las papillas de una anónima lonely crowd en la que cada uno ha perdido lo mejor de sí mismo para componer algo inferior a todos (Murena 2002, p. 266-67).

Suenan los ecos del diálogo con René Guénon, en especial El reino de la cantidad y los signos de los tiempos (1976). Cuestionar la idea de igualdad resulta incómodo, pero no para Murena, ya que opera desde la lógica del símbolo. La igualdad a la que se refiere es la igualdad de la cantidad, de la uniformidad del mundo sígnico. Es la igualdad de la masa que también evoca Jung. La igualdad que reside en la cantidad y desprecia la cualidad es una igualdad que se traduce en uniformidad. En este plano, la igualdad de la democracia moderna equivale al mero número y la deshumanización del hombre. Todo pensamiento simbólico es refractario por excelencia a este tipo de consideraciones. La interpretación de los símbolos es algo que no se puede concretar en masa. Se trata de una experiencia de la pura cualidad. Por ello, se excluye la posibilidad de lo uniforme.

Los áristoi conservan para Murena un gobierno a través de la cualidad, en tanto el gobierno de la democracia burguesa es el gobierno que se expresa en cantidad. El número - vaciado de simbolismo y reducido a sola cifra - es lo que determina quien será el gobernante.

\section{LA PROFANACión DEL Verbo}

En la sección "La voz de Saulo de Tarso" de La cárcel de la mente Murena se pregunta por el estado de la palabra en la sociedad actual. Ella ha dejado de ser poesía, expresión de lo misterioso, lógos en el sentido de San Juan Evangelista, y se vuelve con insistencia sobre "lo que es del César".

Para Murena, San Pablo inventa la propaganda al suponer que todo el mundo debe ser convertido al cristianismo. Frente a los dioses anteriores - tutelares, familiares, tribales - la propuesta del cristianismo paulino se piensa universal. Es necesario que todos se conviertan para que llegue el Reino. Para esto, será necesario montar un aparato de propaganda y coerción a través de la palabra.

[La propaganda] ¿De dónde viene? Este arte con el que el capitalismo occidental ha procurado y procura enloquecer sistemáticamente a la clientela ecuménica (...) Y lo singular resulta que tal arte tiene el más puro origen religioso (...) Pues la propaganda nació como corolario de una iluminación religiosa superior que en ciertas criaturas engendra la necesidad de modificar el alma del prójimo mediante la comunicación espiritualmente compulsiva de una revelación divina (Murena, 2002, p. 317).

El exceso de propaganda religiosa y de guerras de religión termina por generar su contrario en Occidente, es decir, el uso de la propaganda con fines seculares. Tal es el caso, por ejemplo, del enciclopedismo francés, que utiliza medios muy similares para su proyecto iluminista. El desfalco de la palabra llega incluso a la esfera de la educación, que en su sentido moderno no es más que depósito de información y generación de mano de obra: 
"la educación es un tipo de propaganda en el que, bajo el aspecto de información, predomina la comunicación libre, aunque la verdadera educación es la que empuja a cada cual hacia sí, y deja de serlo en la medida en que tiende a domesticar al hombre para que se adecue a un universo rígidamente preestablecido" (Murena, 2002, p. 333).

Guillermo Piro (2002) toma la expresión "visiones de Babel” del ensayo que cierra La cárcel de la mente para su compilación. La expresión es justa para referir la desintegración de la palabra según Murena. El relato bíblico alude a una situación de disgregación y vacío de sentido. Hay una multitud de lenguas que ya no comunican. La palabra se ha vuelto hueca. Si nos remontamos a la etimología semítica de Babel (bab-Il) nos damos con la expresión "Puerta de Dios"; este aspecto simbólico también remarca un cambio importante. Hubo un momento en que las palabras de Babel se podían constituir como puertas-puentes hacia la divinidad, un momento en que el dios no era inaccesible a los hombres. El extravío de Babel es también la pérdida de una clave espiritual de comprensión. El poder hacedor de la palabra ya no habita en el hombre y el Verbo se ha oscurecido. No hay sabiduría, sólo semiótica.

Murena requiere el aspecto trascendente de la palabra:

las palabras son simplemente mensajeras de otra cosa. (...) Y el único momento en que las palabras valen verdaderamente y con verdaderamente quiero decir que son buenas y fértiles - es cuando quien las emite no está hablando por sí, sino que está dejando pasar a través de sí y transmite, mediante palabras, el espíritu de lo divino (Murena y Vogelmann, 2005, p. 38).

La incitación a revivir la experiencia de lo sagrado es bloqueada en el cristianismo por malos representantes espirituales, junto con la pérdida de la lengua sagrada y los cambios operados en la liturgia durante el siglo XX. El lenguaje, tal como lo entiende la filosofía contemporánea, es artefacto autónomo, desvinculado del mundo inmanente o trascendente. A tal punto se vuelve sobre sí mismo que el ser humano pasa a ser su subordinado. Del Verbo divino se pasa a la palabra de los profetas, de los profetas a los poetas, de los poetas a los filósofos, de los filósofos a los lingüistas, de los lingüistas a los publicistas. Tal es el derrotero descendente. Frente a esto, Murena insta a un lenguaje metafórico, donde se dé cuenta de lo inefable. Un lenguaje que vaya más allá de su autorreferencialidad para volverse vehículo de lo trascendente.

Al destacar el carácter metafórico de la palabra poética, Murena resalta que, como el símbolo, es inexacta. La inexactitud radica en que - como toda expresión de lo sagrado - la palabra poética no se basta a sí misma y no puede cerrarse en la autorreferencialidad. La poesía intenta llevar al hombre hacia un experiencia originaria, la experiencia de lo numinoso. Mas este encuentro con lo numinoso no tiene el carácter exacto de la descripción científica, es algo abierto. Ese territorio abierto, inconmensurable, indefinible, misterioso, se muestra a través de la palabra poética. La metáfora es en el ámbito de la palabra lo que el símbolo en el de la imagen.

La palabra babélica es figuración de lo profano sin más, pretende ser ruido. Como palabra sagrada, la poesía intenta recomponer la imagen de algo que siempre se escapa. "La babelización de la escritura indica aguda nostalgia mala del silencio que la gran obra por naturaleza encierra y busca. La catástrofe de la letra escrita testimonia en forma invertida que la literatura surge de la necesidad de Dios" nos dice Murena (2002, p. 436). La palabra profana instaura el ruido, es imagen exacta de lo que quiere ser: desorientación, caos, mentira. El gran problema del hombre moderno es que ya no puede diferenciar el ruido del silencio:

Tanto la tradición islámica como la judía declaran que en el Paraíso Adán hablaba en verso. Esta figura posee muchos sentidos. Uno concierne al habla. Aún hay vestigios en nuestras vidas del lenguaje paradisíaco: en la mirada del amor fluye una palabra muda pero inequívoca, palabra surgida de una proximidad al Centro que hemos perdido. La palabra que nos dio la serpiente, la palabra del Árbol de la Ciencia, es juzgadora, oprime hasta la muerte lo existente. En el otro polo se encuentra la poesía, en la que la palabra caída tiene de nuevo ocasión de tornarse paradisíaca. La poesía existe para salvar al mundo. El lenguaje caído, juzgador, sólo es adjetivo, comentario, charla nociva. La poesía no juzga, nombra mostrando, es sustantivo, crea, salva. Mediante el lenguaje caído la poesía halla para el lenguaje caído la redención de la metáfora (Murena, 2002, p. 439).

No es llamativo que Murena coloque el ensayo "El arte de traducir" dentro de la sección titulada "La sombra de la Unidad", ya que ahí se revela su propuesta en torno a la palabra. Traducir no tiene que ver 
con trasvasar de una lengua a otra, se trata de una operación que va más allá del lenguaje. Afirma que transducere puede entenderse como "llevar algo más allá de sí" (2002, p. 447). Esto es, poner en lenguaje algo que por su propia forma de ser lo excede. Toda poesía es en sí misma una traducción de lo inefable. Traducción, símbolo y metáfora son tres formas de designar una misma operación artística: la "presentización" por medios materiales de algo que no es material.

En La metáfora y lo sagrado Murena habla de un "impulso metafórico" (2002, p. 440). ¿Cómo entenderlo? $\mathrm{Si}$, como lo advirtió Durand (1999), el hombre es un productor de símbolos, el impulso metafórico es la búsqueda incesante de una metáfora verdadera. Así como los símbolos no tienen dueños ni autores, pertenecen a la humanidad en su conjunto, es un error muy común creer que las metáforas - comparaciones - son propiedad del poeta. En este caso, estaríamos frente a una capacidad metafórica profana, anclada netamente en la creatividad y el ingenio de quien escribe. Pero el impulso metafórico remite a algo más complejo, a algo que puede llamarse imaginatio vera. Carl G. Jung la llamó "imaginación activa”. A grandes rasgos, esta imaginación no es el capricho de la mente, sino que se activa cuando la consciencia se deja atrapar, poseer, por imágenes que no le pertenecen en sentido estricto. Son imágenes del colectivo humano. Lo mismo podemos decir para el impulso metafórico de Murena. Es una comparación que se desarrolla a partir de las herramientas del lenguaje caído, pero no caprichosa; es fruto de una asociación misteriosa que atañe a lo humano, no a un individuo en particular. En cualquier caso, no es una asociación al azar. Es la revelación de una correspondencia a nivel profundo, una sincronicidad que nos desoculta algo más allá de la materia.

La palabra poética llega a su grado sumo en los textos sagrados, y la capacidad performativa de los textos sagrados llega a su grado sumo cuando se vuelve plegaria constante. No en vano, al final de La cárcel de la mente Murena rescata a los Padres del Desierto y los Hesicastas. En ellos, la palabra se ha vuelto mantra, ciclo continuo, recitación que busca disolver el ego para posibilitar el reencuentro con la Unidad. Frente a la plegaria que pide, la oración es un puro entregarse, un dejarse estar en la palabra para que aflore lo sagrado:

\footnotetext{
Oración, de oratio, que a su vez proviene de os-oris, boca. Quien pronuncia la oratio se convierte en pura boca, se anula para concentrarse en ser el limpio conducto a través del cual pasa el soplo divino para sonar como alabanza de la Creación de Dios, el Creador: esa armonía cósmica es la suprema beatitud para una criatura que difunde, entonces, betitud. La plegaria es una oración que difiere de categoría. Plegaria, de precor, suplicar. En la plegaria se pide algo. A la criatura no le basta con que el paso del hálito del Creador la confirme en esa inmortalidad que es su recuerdo de la Unidad: pide, necesita pruebas que se refieran a su particular persona dentro de lo creado (Murena, 2002, p. 457).
}

\section{ARS SACRA}

La reflexión de Álvarez Murena sobre el Kali Yuga debía tener una sección dedicada al arte. Ya que, como lo señala en La cárcel de la mente, "el arte es el alma de una época" (2002: 349).

$\mathrm{Al}$ acercarse al arte de vanguardia y post-vanguardia constata que se ha perdido cualquier componente tradicional. El pensamiento materialista tiende sobre las obras un manto de profanidad. Las considera en sus aspectos materiales y las adora como obras: la perfección de la técnica, su significación, el tiempo histórico en que fueron concebidas, el campo artístico. En las reflexiones posmodernas sucede lo mismo: se toma al símbolo por lo simbolizado. Entonces, ya no hay vínculo con nada de "más allá" (metáfora), sino que todo se queda en el "más acá", arrobado en su propia finitud.

la sociedad de masas —en la que la burguesía se disuelve-, si bien no quiere en verdad cultura, reclama sus circenses con apariencia cultural. Y el surrealismo (...) ofrecía a la industria cultural una ocasión óptima porque los trazos surrealistas eran más fáciles de asimiliar o imitar y reproducir (...). Así aconteció que el precepto del catecismo surrealista que afirmaba que "la poesía debe ser hecha por todos" se transformó de tal suerte que quien visite los salones y museos en que se exhibe el arte hoy comprobará que ha quedado convertido en otro precepto que dice que "la poesía puede ser hecha por cualquiera" (2002, p. 347). 
Murena destaca que en el arte del siglo XX se da algo paradójico: por primera vez aspira a la autonomía total. Considera esto un autismo artístico que busca expresar una inexistente mismidad. Se ha perdido el último vestigio de un arte sacro y queda sólo un arte profano. Por otro lado, con el adjetivo "circenses" señala también la superficialidad del arte en la sociedad de masas. El hombre unidimensional reclama una cultura y un arte que secunden la ausencia de profundidad. El kitsch remarca que nada numinoso anida ya en el arte. La tecnología ha "desventrado" (2002, p. 253) el mundo, ha puesto lo misterioso por fuera del templo y se ha complacido en decir que nada de misterioso existe en el misterio. En términos generales, Titus Burckhardt refiere la idea de este modo: "La ciencia y el arte de la época moderna evolucionan en el sentido horizontal de la trama "material"; la ciencia y el arte de la Edad Media, al contrario, se refieren a la vertical de la urdimbre trascendente" (1982, p. 52).

En La metáfora y lo sagrado señala lo siguiente:

Por feliz y libre que en su verdad un objeto aparezca en la obra, siempre recordará, habrá de recordar —esto es condición de la obra - su lugar originario. Todos los elementos de la obra de arte señalan una distancia: junto con el movimiento que la engendra, la distancia es el fundamento de la obra (2002, p. 450).

¿A qué se refiere Murena con la idea de distancia? Evidentemente, aquí suenan los ecos de Titus Burckhardt, una cita recurrente de Murena. Para el crítico suizo el fin último del arte sagrado

no es evocar sentimientos o transmitir emociones; es un símbolo que utiliza elementos simples y primordiales, una pura alusión, cuyo objeto real es inefable. Es de origen angélico porque sus modelos reflejan realidades supraformales. Al recapitular en parábolas la creación — “arte divino" - el arte sagrado demuestra la naturaleza simbólica del mundo y desvincula el espíritu humano de los hechos toscos y efímeros (1982, p. 3).

Con la distancia señala, en principio, la condición del arte profano desde Grecia hasta la modernidad (con la excepción de la Edad Media). El arte sacro, que se rige por normas y reglas establecidas desde muy antiguo, busca "presentizar" una ausencia, mostrar algo que es, por definición, misterio y distancia. Esto sólo es posible a través del símbolo y con consciencia del fracaso inevitable. Con la perspectiva renacentista, la distancia se hace cada vez más patente, pero ahora es distancia del mundo; el hombre se siente cada vez más alejado de las cosas que lo rodean, ya no forman parte de su espíritu y se hallan fuera de sí.

La distancia, en el arte sagrado, era por completo diferente. Era consciencia de una distancia con el Principio que anima el cosmos, y era también comunión con lo que se encuentra en lo inmediato. Hombre y árbol comparte una misma condición: están alejados del Principio divino. El arte vuelve al hombre consciente de esa distancia, que debe ser remontada.

El arte sagrado tiene la premisa de acercar algo inefable a este mundo. Y como lo inefable no puede irrumpir sino a través del símbolo, todo arte sagrado debe ser simbólico.

Esa nostalgia no constituye el tema sino la esencia del arte (...) Se trata de la esencia que resulta evidente de la operación básica del arte: en la metáfora se "lleva" (fero) "más allá" (meta) el sentido de los elementos concretos empleados para la forja de la obra. ¿Se llevan más allá?: llevar más allá lo sensible y mundano significa traer más acá el otro mundo. La metáfora consiste en romper las asociaciones de uso común de los elementos concretos e instalarlos en otro contexto en el cual — gracias a la súbita distancia que les confiere el desplazamiento- cobran nueva vivacidad, componen otro mundo (Murena, 2002, p. 401).

Se cumple así con la idea inicial de concebir al arte como "mediador entre este mundo y el otro". En esa mediación concurren dos actos. El primero, acercar lo divino al mundo terrenal para poder expresarlo; lo segundo, la elevación de lo material por la cercanía con lo trascendente. Este segundo punto no es menos importante. Como también lo piensa Marechal en su Descenso y Ascenso del Alma por la Belleza, el trabajo artístico es mejorativo. Ayuda a la transustanciación de lo material en lo espiritual; y por esto no destruye los materiales con los que trabaja — como es el caso de la técnica titánica- sino que los ennoblece, cual proceso alquímico. 


\section{CONCLUSIONES: RESACRALIZAR LA EXISTENCIA}

Para cerrar nuestro recorrido, diremos algunas palabras sobre el hecho de vivir en América. Para el autor, el americano es un "europeo desterrado" que, incapaz de afrontar la realidad que le toca en suerte, pretende encubrirla mediante el desprecio por "lo dado" del lugar en que se vive (2002, p. 245). La nostalgia por Occidente vuelve al sujeto americano un desposeído que no puede regresar, pero tampoco tiene dónde ir.

La apuesta de Murena radica en resucitar el viejo vínculo del hombre con lo sagrado. Quizás el americano se sienta desplazado de su geografía tradicional, pero la sensación de desarraigo y pérdida - que comparte con el norteamericano y el europeo- tiene su raíz en la obturación de lo sagrado de su horizonte vital. Pero en América, lo sagrado está aún vivo a flor de piel y puede constituirse como un refugio donde la existencia se rehaga. El indígena vive aún en el mundo sacralizado; cualquiera de las culturas tradicionales de Medio Oriente y Asia oriental sigue orquestándose en torno a lo sacro. Sólo la Europa post-renacentista y todas sus ramificaciones posteriores han desertado de ese mundo para constituir una existencia autónoma, escindida de cualquier tipo de relación con lo divino.

La identidad americana - al menos la que considera Murena, es decir, el mestizo citadino y los descendientes de inmigrantes - está en conflicto porque no encuentra aún las fuerzas suficientes para dar un salto de independencia cultural y espiritual de Europa. Acarrea los problemas de un continente lejano para adscribir a una identidad cultural decadente y cansada. Su territorio no está surcado por las huellas de la antigua cristiandad medieval, último refugio tradicional de Occidente. Por ello, con tanta mayor soltura se amolda al pensar titánico.

La propuesta de hombre futuro se ancla en dos aspectos antinómicos y, quizás por eso, complementarios. Uno angustiante y el otro revivificante. El aspecto angustiante - de cariz heideggeriano- se expone en el punto 17 de "Los nihilistas". Allí entiende que, considerada a fondo, la vida de Occidente no presenta más alternativas que la repugnancia o la resignación. La vida tecnocrática termina doblegando al hombre, obligándolo a asumir roles y papeles que no le son propios, hasta que sucumbe a la poderosa red y opta por el fármaco de la cotidianeidad. Es tanto más fácil estar dormido que soportar la lucidez (2002, p. 306). Frente a esto, la única posibilidad es rebelarse. Rebelarse consiste en llegar al límite, y el límite consiste en una extrema lucidez. La desestructuración de lo cotidiano, el desarme del entramado de la rutina, la renuncia a la vida media son los pasos de esta rebeldía que conduce, en última instancia, a la aceptación sin miedo de la muerte.

Así aparece el segundo aspecto de la propuesta de Murena, el aspecto vivificante. Pero la recuperación de lo sagrado es un camino de individuación y búsqueda que se da lejos de la masa. Recuperar la salud social consciente en entender que la curación no radica en la modificación del ambiente externo. Más bien, radica en asumir y transformar el ambiente interno. Lo primero es delegar, sacar fuera de sí; lo segundo, es asumir una vida auténtica.

Ahora bien, este camino de individuación espiritual no se comprende como un ejercicio del autismo que sustrae al hombre de la sociedad. Depositar la administración de lo sagrado en el exterior y vivirlo como algo externo a la persona, atrofia la capacidad de religarse con lo sacro interior. A su vez, lo sacro interior es tanto más complejo y el hombre debe hacer un camino de exploración hacia su intimidad para dar con esa sacralidad, de la cual se terminará nutriendo lo sacro exterior. He aquí la clave para resacralizar el mundo.

\section{REFERENCIAS}

Burckhardt, T. (1982). Principios y métodos del Arte Sagrado. Buenos Aires, Argentina: Lidium.

Cristófalo , A. (1999). Murena, un crítico en soledad. En Historia crítica de la literatura argentina: la irrupción de la crítica (Vol. 10). Buenos Aires, Argentina: Emecé.

Djament, L. (2015). Murena: un anómalo en la revista Sur. Recuperado de http://www.espaciomurena.com/8472/.

Durand, G. (1999). Ciencia del Hombre y Tradición. El Nuevo Espíritu Antropológico. Barcelona, España: Paidós. 
Estrin , L. (2002). Héctor Álvarez Murena: el secreto claro. En Historia del ensayo argentino. Intervenciones, coaliciones, interferencias. Buenos Aires, Argentina: Alianza.

Frugoni de Fritszche, T. (1985). Murena. Buenos Aires, Argentina: El imaginero.

Gasquet, A. (2008). El Orientalismo Argentino (1900-1940): De La Revista Nosotros Al Grupo Sur. Working Papers, 22.

Guénon, R. (1976). El reino de la cantidad y los signos de los tiempos. Madrid, España: Ayuso.

Guénon , R. (2003). Esoterismo Cristiano. Buenos Aires, Argentina: Obelisco.

Hani, J. (1998). La Realeza Sagrada: Del Faraón al Cristianisimo Rey. Palma de Mallorca, España: José J. de Olañeta. Hani, J. (2005). Mitos, Ritos y Símbolos. Palma de Mallorca, España: José J. de Olañeta.

Ighina , D. (2000). Murena: negación y recomienzos de la historia. Inti, revista de literatura hispánica, 52.

Jung, C. G. (2014). Obra Completa 10. Civilización en Transición. Madrid, España: Trotta.

Mattoni , S. (2003) Las formas del ensayo en la Argentina de los años '50. Córdoba, Argentina: Editorial FFyH.

Mattoni , S. (2012). Prólogo. En La metáfora y lo sagrado. Buenos Aires, Argentina: El cuenco de plata.

Murena, H. A. (2002). Visiones de Babel. Ciudad de México, México: FCE.

Murena , H. A. y Vogelmann, D. (2005). El Secreto Claro (Diálogos). Córdoba, Argentina: Alción.

Piro, G. (2002). Introducción. En H.A. Murena, Visiones de Babel. Ciudad de México, México: FCE.

Poggiese, D. (2006) El proyecto de H.A. Muren: la espiral infinita. Revista Pilquen, 8. Recuperado de http://www.sc ielo.org.ar/scielo.php?script $=$ sci_arttext\&pid=S1851-31232006000100002.

Schmucler, H. (2013) H. A. Murena. Recuperado de http://www.espaciomurena.com/7310/.

Tse, L. (2002). Tao Te King. Madrid, España: Edaf.

Vogelmann, D. J. (06 de julio de 1975). Murena y el mundo hermético. La Nación. Recuperado de https://www.es paciomurena.com $/ 5180 /$

\section{Notas}

1 Si bien, como señala Cristófalo, Murena se vuelve ilegible para la revista Contorno, es importante resaltar que su interés por las filosofías y religiones de Oriente no son ajenas a los intereses de la revista Sur. Rescatamos esta afirmación de Axel Gasquet: «Después de Fatone la atracción filosófica del Oriente será un hecho institucionalizado y la misma ejercerá una gravitación perceptible en escritores del grupo Sur como Eduardo Mallea, Victoria Ocampo, Jorge L. Borges y Héctor A. Murena» (2008, p. 16).

2 Aquí trabajaremos con la edición de Fondo de Cultura Económica, que, bajo el título Visiones de Babel (2002), compendió los libros La cárcel de la mente y La metáfora y lo sagrado (junto con otros textos narrativos y poéticos). En tanto que para El secreto claro utilizaremos la reedición de Alción (2005).

3 La síntesis de un pensamiento anclado en la tradición alemana que dialoga con las filosofías de oriente es remarcado por Axel Gasquet, que señala: «Los rasgos orientales del peculiar escritor y ensayista Héctor A. Murena se observan, indirectamente, por la ascendencia del linaje filosófico alemán en su obra. Las huellas del romanticismo y el existencialismo filosófico germanos son percepibles en casi todos sus ensayos. Una síntesis de estas influencias a la par germánticas y orientales puede encontrarse en El secreto claro» (2008, p. 17). Acordamos en el postulado general, aunque -como hemos referido- el diálogo con Oriente y las corrientes esotéricas no está mediado por la filosofía alemana, sino que se recibe de primera mano a través de las traducciones al francés. Dedicamos especial atención a Jung porque su caso es semejante al de Murena. Provienen de campos no especializados en religión (la psicología, la literatura) pero advierten que el olvido de lo sagrado en Occidente tendrá efectos devastadores. Igualmente, colocan en el centro de sus reflexiones la relación entre el hombre actual y la religión. 